\title{
Knowledge Structure Analysis on Educational Technology Based on Citation Analysis
}

\author{
https://doi.org/10.3991/ijet.v15i05.13331 \\ Junxiao Liu, Xiangzeng Meng $(\bowtie)$ \\ Shandong Normal University, Jinan, China \\ mxzesdnu.edu.cn \\ Changsheng Chen \\ Shandong Youth University of Political Science, Jinan, China
}

\begin{abstract}
Educational technology is a new subject that integrates the merits of multiple disciplines. Under the trend of interdisciplinary integration, it is very meaningful to explore the knowledge exchange between disciplines, clarify the structure of each discipline, and thus promote the development of educational technology. Extracting data from eight core journals on educational technology, this paper investigates the integration between educational technology and other disciplines from the perspectives of references and citations. The disciplines were divided by the standard of China National Knowledge Infrastructure (CNKI). The results show that: educational technology has a stable disciplinary structure, featuring a high self-citation rate (i.e. the tendency to cite the literature within the discipline); educational technology has frequent knowledge exchanges with pedagogy-related disciplines, and exerts a major impact on the other secondary disciplines of pedagogy; educational technology actively absorbs the knowledge of other disciplines, and communicates frequently with external disciplines like psychology, computer science, library and information science.
\end{abstract}

Keywords-Educational technology, citation analysis, interdisciplinary integration, knowledge structure

\section{Introduction}

Educational technology is a new subject developed by the interdisciplinary integration. Many scholars at home and abroad have discussed or studied the interdisciplinary characteristics of educational technology from different perspectives. Educational technology is an interdisciplinary subject formed by the infiltration and fusion of educational theory and modern technology [1]. Ren and Gu [2] stated that in the discipline theory construction, the research area of educational technology has been continuously expanded and diversified, and then through the continuous absorption and reference of other disciplines' knowledge, it has developed a theoretical system with Chinese characteristics. According to the 2016 MIT Online Education Policy 
Initiative, higher education urgently needs deeper research integration in areas affecting learning, and it is recommended that interdisciplinary cooperation between education and other areas be strengthened as the top priority strategy of higher education reform [3]. The interdisciplinary research cooperation between educational technology and related fields not only contributes to achieving related research results, but also can stimulate the imaginative and innovative research, and help to solve the practical and complex problems in teaching and learning [4]. Among various educational technology-related research fields, online teaching and learning, learning science and neuroscience, and the training of interdisciplinary talents in the field of instructional design can all become new areas of interdisciplinary research [5].

Educational technology originated from the visual instruction movement at the beginning of the 20th century. It has developed with the infiltration of many disciplines. As a field of interdisciplinary research and practice, educational technology continuously integrates the theories and methods of pedagogy, psychology, systems science, sociology, as well as media technologies such as audiovisual media, computer and network technology in the course of disciplinary development [6]. From the existing research, the generation of educational technology depends on the knowledge of many other disciplines in addition to its own disciplines, and the literature of educational technology is also cited by other disciplines. Therefore, it is an indisputable fact that educational technology is an interdisciplinary discipline. In the existing studies on the scope and structure of educational technology, most focus on qualitative descriptions, judgments, discussions, etc., but there is a lack of research that quantitatively reveals the discipline knowledge structure of educational technology and its changing trends. With the continuous development and integration of various disciplines, the interdisciplinary nature of educational technology has become more apparent. It has become an important topic on how to quantitatively describe the interdisciplinary feature of educational technology and its evolution process.

In view of the above, extracting data from eight core journals on educational technology, this paper analyses the interdisciplinary evolution trend of educational technology in China based on citation analysis, and investigates the integration between educational technology and other disciplines from the perspectives of references and citations.

\section{Related Research at Home and Abroad}

As social phenomena become more complex and multi-dimensional, interdisciplinary ability to solve problems has become increasingly important without relying on the expertise of a single discipline, and has become a common phenomenon in scientific development [7]. Porter et al. Pointed out that the characteristics or status of the paper reference is logically the best measure for interdisciplinary research. The interdisciplinary measurement can be carried out by examining the discipline categories of the paper reference to define the measurement indicators [8]. Foreign studies on disciplinary structure and evolution started relatively early. They were mainly carried out using scient metrics and social network analysis methods, and 
based on this maps of scientific knowledge were also drawn. Scientometrics methods for studying the disciplinary structure and evolution include cluster analysis, cooccurrence analysis, and co-citation analysis etc. White and McCain [9] performed author co-citation analysis, factor analysis, and multidimensional scale analysis on citations of 12 journals in the field of library and information from 1972 to 1995, and obtained 12 research directions in this discipline. Leydesdorff [10] proposed that the citation relationship between journals is of great value, and different analysis methods can be used to obtain results with different emphasis. R. Agarwal took ISR journals as the research object and collected reference and citation data from 2012 to 2015, which confirmed the multidisciplinary nature of the information system discipline and the continuous expansion of discipline boundaries [11]. Krapivsky and Redner [12] pointed out that the citing literature is not only cited in the same field, but also cited and disseminated in similar and different fields, thereby promoting the generation of new knowledge, and the absorption and diffusion of knowledge through subject papers can also be good Geo-measure the cross-fusion of knowledge in this field with other fields.

In China, the disciplinary structure and evolution of educational technology has always attracted the attention of researchers in different fields. Scholars mainly conduct analysis on these issues from the perspectives of co-word analysis, co-citation analysis, and coupling analysis based on scient metric methods and multivariate statistical methods, and use visualization tools to show their analysis results. Cai and Huang [13] conducted the citation analysis on the citations of 9,329 source documents in the source journals of CSSCI from 2000 to 2009 using the information visualization software CiteSpace, confirmed the relevant disciplines of educational technology, and analyzed their inter-knowledge flows and trends. Lan [14] analyzed the frontiers and hotspots of international educational technology research and the representative figures and academic groups of international educational technology research by using scientific knowledge map visualization analysis technology. Liu et al. [15] analyzed the interdisciplinary situation and themes of educational technology based on Web of Science data. Zhou et al. [16] analyzed the scientific research output competitiveness of China's educational technology discipline research institutions. There is relatively little attention on the interdisciplinary situation of educational technology in the existing research, and there is a lack of research to quantitatively reveal the changing trend of interdisciplinary education technology. Yang et al. [17] pointed out that a series of problems involved in the practice of education informatization must be integrated from information science, education, computer science, psychology, cognitive science, neuroscience, and brain science. Knowledge resources in multidisciplinary fields such as science, politics, management, economics, and even philosophy. The task of scientists has shifted towards interdisciplinary issues rather than single disciplines [18]. For the development of educational technology, interdisciplinary research has gradually become a consensus, and the future trend of discipline talent training [19]. 


\section{$3 \quad$ Research Content and Methods}

\subsection{Data source}

The Chinese Citation Database (CCD) was selected as the source data source. Its comprehensive and diverse field selection can provide relevant high-integrity data for the research. In this study, eight educational technology-related journals in CSSCI were selected as data sources, namely China Educational Technology, E-education Research, Modern Education Technology, Open Education Research, Distance Education in China, Modern Distance Education Research, Modern Distance Education, and Journal of Distance Education. A total of 5,945 papers were retrieved in CSSCI from 2014 to 2018. The fields such as title, author, institution, keywords, abstract, Chinese classification number, reference, and cited literature were selected to derive the search results.

\subsection{Research methods}

The references and citations of the main journal literatures in the educational technology can reflect the source and diffusion structure of this discipline. Journal literature has a fixed subject attribute and a clear classification, while other types of literature, such as monographs and newspapers, do not have a uniform classification, and they only account for a small part of all documents in quantity. Therefore, to make the classification results more accurate, all references and citations of the literature were first filtered, leaving only the journal documents identified by the letter "J", and then discipline classification was made by adopting the strategy of categorizing the references and citations into the corresponding discipline in their respective journals. Specifically, domestic literature refers to the journal classification standards in CNKI and the journals were classified into corresponding disciplines; foreign literature was classified into the discipline of different journals according to the WOS discipline classification standard in the Web of Science database. There are 12,165 journals in CNKI comparison table, belonging to 185 disciplinary categories. Based on this, the 8 journals included in CSSCI related to educational technology are all parts of educational theory and educational management. To ensure accurate analysis, this paper categorizes China Educational Technology, E-educational Research, and Modern Educational Technology as the discipline of educational technology, and Open Education Research, Distance Education in China, and Journal of Distant Education, Modern Distance Education Research, and Modern Distance Education as the disciplines of educational technology and distance education.

This paper uses citation analysis to analyze 51,088 references and 35,810 citations from these eight educational technology journals. Citation analysis is the use of mathematical and statistical methods to analyze journal citations and reveal their quantitative characteristics and internal laws [12]. Citation is the main method for the dissemination and exchange of scientific knowledge. Using citation analysis to analyze the knowledge input and knowledge output of educational technology, it is helpful to 
investigate the cross-integration of educational technology and other disciplines, understand the position and distribution of the educational technology in the entire disciplines, and better grasp the development direction of the disciplines. It also provides a reference for the knowledge reserve of educational technology professionals.

\subsection{Results analysis}

References analysis: 5,945 papers have a total of 51,088 journal references, including 43,457 Chinese journal papers, and 7,631 foreign journal papers. During the process of dividing Chinese references to the disciplines of the journals, there were 1,363 journal papers that could not be identified, and a total of 42,095 valid Chinese references were obtained. Table 1 shows Chinese references and related disciplines.

Table 1. Chinese references and related disciplines

\begin{tabular}{|l|c|c|}
\hline \multicolumn{1}{|c|}{ Disciplines } & Number of references & Proportion (\%) \\
\hline Educational Technology & 15402 & 36.6 \\
\hline Distance Education & 8929 & 21.2 \\
\hline Educational Theory and Educational Management & 3997 & 9.5 \\
\hline Comprehensive Education & 2667 & 6.3 \\
\hline Higher Education & 1731 & 4.1 \\
\hline Library Information and Digital Library & 1012 & 2.4 \\
\hline Educational Informatization & 764 & 1.8 \\
\hline Basic Science & 728 & 1.7 \\
\hline Information Technology education & 790 & 1.9 \\
\hline Secondary Education & 803 & 1.9 \\
\hline Electronic Information Science & 519 & 1.2 \\
\hline Computer Software and Computer Application & 510 & 1.2 \\
\hline Psychology & 484 & 0.9 \\
\hline Adult Education and Special Education & 384 & 0.7 \\
\hline Comprehensive Science and Technology (class b) & 304 & 0.7 \\
\hline Foreign Language and Literature & 290 & 0.7 \\
\hline Vocational Education & 282 & 0.7 \\
\hline News and Media & 277 & 0.5 \\
\hline Economy and Management & 208 & 0.3 \\
\hline Philosophy & 143 & 0.3 \\
\hline Political and Military Law & 111 & 0.3 \\
\hline World Literature & 105 & \\
\hline
\end{tabular}

For the 7,631 foreign references, the journal of each reference was checked according to the corresponding comparison table of journal discipline based on the WOS core compilations. A total of 5,991 documents can be mapped to disciplines, including 5,017 core journals and 974 ESCI journal papers. Core journals accounted for $78.5 \%$. This indicates that the foreign language documents referenced by Chinese educational technology source journals are mainly WOS core journals. Table 2 shows the analysis of 5,991 foreign references. 
Table 2. Foreign references and related disciplines

\begin{tabular}{|l|c|c|}
\hline \multicolumn{1}{|c|}{ Disciplines } & Number of references & Proportion (\%) \\
\hline Education \& Educational Research & 3282 & 54.8 \\
\hline Psychology & 1140 & 19.0 \\
\hline Computer Science & 417 & 7.0 \\
\hline Management & 209 & 3.5 \\
\hline Operations Research \& Management Science & 149 & 2.5 \\
\hline Information Science \& Library Science & 134 & 2.2 \\
\hline Linguistics & 83 & 1.4 \\
\hline Engineering & 70 & 1.2 \\
\hline Business & 55 & 0.9 \\
\hline Neurosciences & 41 & 0.7 \\
\hline Nursing & 39 & 0.7 \\
\hline Communication & 34 & 0.6 \\
\hline Ergonomics & 24 & 0.4 \\
\hline Telecommunications & 23 & 0.4 \\
\hline Health Care Sciences \& Services & 21 & 0.4 \\
\hline
\end{tabular}

- From the perspective of Chinese reference, the self-citation rate of educational technology is relatively high, and the self-citation rate of related disciplines was $57.8 \%$, of which $36.6 \%$ were from three magazines of educational technology, $21.2 \%$ were from distance education, $2.7 \%$ from education informatization and information technology education, and $23.4 \%$ from other education-related disciplines. Among other disciplines, library information and digital libraries occupied the largest proportion, reaching up to $2.4 \%$; the basic science accounted for $1.7 \%$, electronic information science accounted for $1.2 \%$, computer software and computer applications accounted for $1.2 \%$, and psychology accounted for $1.2 \%$. There were some disciplines with the number of references over 100 times, occupying less than $1 \%$, namely comprehensive science and technology (class B), foreign languages and literature, news and media, economy and management, philosophy, political and military law, and world literature. On the one hand, this phenomenon reflects that after years of development, educational technology has formed a relatively comprehensive and systematic basic theoretical system, featuring a stable discipline structure, and the research results in the discipline can basically meet the needs of the discipline development; on the other hand, it also shows the weak information absorption capacity of the educational technology discipline, so it is not enough to digest and absorb the new ideas and methods generated by other disciplines, and then enrich and develop the connotation and extension of the discipline.

- Of the foreign language references, education and educational research related disciplines accounted for $54.8 \%$, including education \& educational research, interdisciplinary education, and special education. Among other disciplines, psychology had the highest proportion, reaching 19\%, of which educational psychology and experimental psychology accounted for the highest, $10.4 \%$ and $5.9 \%$ respectively. In addition, there were interdisciplinary psychology, applied psychology, developmental psychology, clinical psychology, mathematical biology, and biolog- 
ical psychology, etc. The disciplines with more references also include computer science, management science, operations research and management science, information science and library science: computer science accounted for $7 \%$, management science for $3.5 \%$, operations research and management science for $2.5 \%$, and information science and library science for $2.2 \%$. Computer science involves software engineering, artificial intelligence, cybernetics, information systems, interdisciplinary applications, theories and methods, hardware and architecture, among which software engineering and artificial intelligence accounted for the largest proportion. Also, among the disciplines of the references, language and linguistics accounted for $1.4 \%$, business and economics for $0.9 \%$, and neuroscience, nursing, communications, ergonomics, telecommunications, health care science and services, etc. had certain proportion.

Citation analysis: By processing the citation literature, a total of 35,810 valid citation literatures were obtained. Table 3 shoes the disciplinary distribution of citation literature.

Table 3. Disciplinary distribution of cited literature

\begin{tabular}{|l|c|c|}
\hline \multicolumn{1}{|c|}{ Disciplines } & Number of cited literature & Proportion (\%) \\
\hline Educational Technology & 4989 & 13.9 \\
\hline Comprehensive Education & 4771 & 13.3 \\
\hline Educational Theory \& Educational Management & 3535 & 9.9 \\
\hline Secondary Education & 3071 & 8.6 \\
\hline Distance Education & 1948 & 5.4 \\
\hline Educational Informatization & 1758 & 4.9 \\
\hline Higher Education & 1634 & 4.6 \\
\hline Basic Science & 1356 & 3.8 \\
\hline Computer Software and Computer Application & 1318 & 3.7 \\
\hline Vocational Education & 966 & 2.7 \\
\hline Comprehensive Science and Technology (class B) & 761 & 2.1 \\
\hline Electronic Information Science & 702 & 2.0 \\
\hline Elementary Education & 686 & 1.9 \\
\hline Information Technology Education in Elementary and & 618 & 1.7 \\
\hline Secondary Schools & & 1.6 \\
\hline Adult Education and Special Education & 586 & 1.6 \\
\hline Information Technology Education & 560 & 1.3 \\
\hline Medical Education and Medical Frontier Science & 447 & 1.2 \\
\hline Library Information and Digital Library & 439 & 1.1 \\
\hline Sociology and Statistics & 376 & 0.7 \\
\hline Economy and Management & 340 & 0.7 \\
\hline Foreign Language and Literature & 251 & \\
\hline Chinese Literature & 249 & \\
\hline
\end{tabular}

Table 3 shows that from the perspective of citation disciplines, the self-citation rate of educational technology was $19.4 \%$, of which educational technology accounted for $13.9 \%$, distance education for $5.4 \%$, education informatization for $4.9 \%$, and information technology education for $3.3 \%$ (elementary and secondary school information 
technology education accounted for $1.7 \%$ ). Other education-related disciplines accounted for $45.6 \%$ (specifically, comprehensive education $13.3 \%$, education theory and education management $9.9 \%$ ). In addition, basic science accounted for $3.8 \%$, computer software and computer applications accounted for $3.7 \%$, comprehensive science and technology (class B) accounted for $2.1 \%$, electronic information science accounted for $2 \%$, and library information and digital libraries accounted for $1.2 \%$. From the distribution of citation disciplines in educational technology, it can be seen that the diffusion degree of educational technology knowledge is relatively wide, especially in other related disciplines of education, which extensively borrow the theories and methods of educational technology disciplines. This indicates that the educational technology exerts a major impact on other education-related disciplines.

Comprehensive analysis: It is the focus of this research to take statistics on which subjects the educational technology disciplines have absorbed in formal communication, and analyze which subjects and research methods of the educational technology disciplines have been used for reference. Through data analysis, the trend of cross integration of educational technology disciplines and other disciplines is provided, which provides a reference for the knowledge reserve of educational technology professionals and provides ideas for the diversified development of educational technology disciplines. To this end, the author first uses VBA self-programming program to clean and organize the data and convert it into a .csv file. Because there are many nodes, the disciplines that have been cited more than 1,000 times in the reference disciplines and citation disciplines are listed separately, as shown in Table 4.

Table 4. Subjects referenced or cited more than 1,000 times

\begin{tabular}{|l|c|c|}
\hline \multicolumn{1}{|c|}{ Disciplines } & Reference times & Citations \\
\hline Educational Technology & 15402 & 4989 \\
\hline Distance Education & 8929 & 1948 \\
\hline Educational Theory and Educational Management & 3997 & 3535 \\
\hline Educational Synthesis & 2667 & 4771 \\
\hline Higher education & 1731 & 1634 \\
\hline Library, Information and Digital Library & 1012 & \\
\hline Secondary education & & 3071 \\
\hline Educational Information & & 1758 \\
\hline Basic Science Comprehensive & & 1356 \\
\hline Computer software and computer applications & 1318 \\
\hline
\end{tabular}

\section{$4 \quad$ Interdisciplinary Topic Analysis of Educational Technology}

The identification of interdisciplinary topics is of great significance for detecting research frontiers, hotspots, and new growth points of the discipline, and promoting interdisciplinary cooperation and sharing. This article selects data from the field of educational technology in the past five years (2014-2018) as measurement data to identify topics that intersect with other disciplines in this discipline. According to the interdisciplinary analysis of educational technology in the previous section, the subjects closely related to educational technology are distance education, educational 
theory and education management, comprehensive education, higher education, library information and digital library, secondary education, educational information, Basic science synthesis, computer software and its applications. This article only selects the cross-discipline "Library Information and Digital Library" of educational technology for cross-theme analysis.

Through the advanced search function of the CNKI database, the search conditions are set to "references = 12 core journals of library and information science"; the time of publication is selected from 2014 to 2018. Source periodical $=8$ journals of educational technology. Source category selection is CSSCI. The literatures of the core journals of educational technology from 2014 to 2018 were cited for statistical analysis of downloads. The VosViewer tool was used to analyze the 653 educational technology papers that cited library and information science journals from 2014 to 2018. The results are shown in Fig 1.

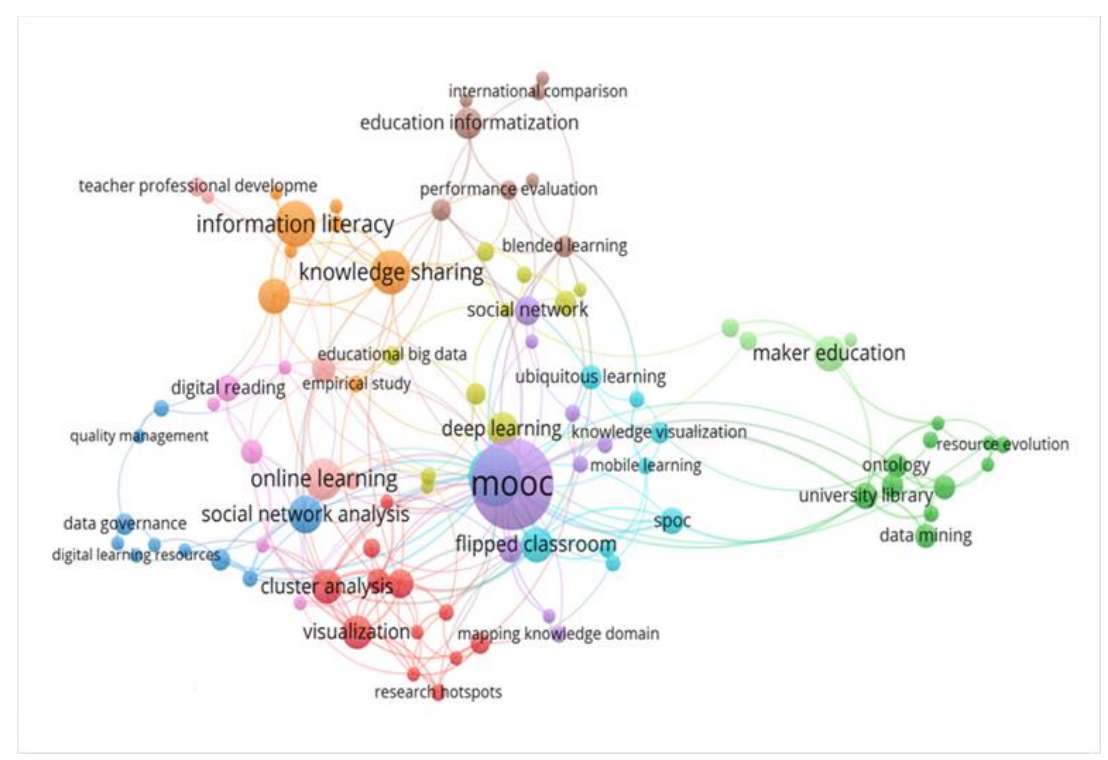

Fig. 1. Keyword clustering in educational technology and library information, digital libraries.

Keyword cluster analysis was performed on 653 educational technology papers that cited library and information science journals from 2014 to 2018, and the following eleven types of research topics were obtained.

- Information visualization research: Research topics include cluster analysis, coword analysis, distance education, educational technology, knowledge mapping, research frontier, research hotspot, research hotspots, research topic, visualization analysis.

- Research on data mining and knowledge service: Research topics include data mining, e-learning, knowledge innovation, knowledge service, learning cell, learn- 
ing cell system, learning resources, ontology, open knowledge community, resource evolution, university library.

- Research on smart education and educational big data: Research topics include big data in education, data governance, digital learning resources, micro-lecture, multidimensional scaling analysis, open university, quality management, smart education, social network analysis, user satisfaction.

- Artificial intelligence and deep learning: Research topics include artificial intelligence, college students, deep learning, digital education resources, educational big data, educational informatization, learning analysis, open education, structural equation model.

- Application of scient metrics in educational technology: Research topics include clustering analysis, content analysis, influence factors, information technology, learning community, mapping knowledge domain, MOOC, social network, technology acceptance model.

- Flipped classroom and mobile learning: Research topics include flipped classroom, knowledge element, knowledge map, knowledge visualization, learning performance, meta-analysis, mobile learning, SPOC, ubiquitous learning.

- Application of empirical study: Research topics include AHP, college teacher, empirical study, influencing factors, information literacy, k-12 students, knowledge sharing, self-efficacy.

- Learning performance evaluation: Research topics include analytic hierarchy process, blending learning, education informatization, information literacy assessment, international comparison, literature review, performance evaluation, visualized analysis.

- Digital reading: Research topics include cite space, digital reading, empirical research, influencing factor, new media, web-based learning.

- Learning analytics: Research topics include continuance intention, data literacy, learning analytics, online learning, teacher professional development.

- Maker education: Research topics include case study, maker, maker education, maker space.

It is found through analysis that educational technology has borrowed and absorbed the theories and methods of library information and digital libraries in the aspects of visualization analysis, data mining, mobile learning, learning analysis, and scient metrics applications. And methods have played an active role in promoting the interdisciplinary development of educational technology.

\section{Conclusion}

From the perspective of disciplines and citations, this paper carries out an in-depth study of the disciplinary integration, knowledge structure and knowledge evolution between educational technology and other disciplines. Through analysis for the knowledge input and knowledge output of educational technology, the following conclusions are drawn: 
- Educational technology is an applied discipline integrating the merits of other disciplines: It can exchange and share knowledge with multiple disciplines. The educational technology subject enjoys a higher self-citation rate, and it is more inclined to cite the literature within the discipline. This may be due to the sociological nature and the Matthew effect of the educational technology, which restricts its close communication with other disciplines.

- Educational technology are closely linked with other education-related disciplines: Educational technology actively absorbs theories and methods of pedagogy-related disciplines such as education theory and education management, comprehensive education, and higher education, while pedagogy-related disciplines have borrowed more from the theory and methods of educational technology. Obviously, the disciplines such as comprehensive education, education theory and education management, secondary education, education informatization, higher education, vocational education, adult education and special education, and medical education, etc. have frequent knowledge exchanges with educational technology. This shows that the theory and methods of educational technology have been recognized and used for reference in other related disciplines of pedagogy, and that the educational technology has a great influence on other secondary disciplines of education.

- Educational technology has a stable disciplinary structure: By comparison of reference and citation disciplines, it's found that the five disciplines of educational technology, distance education, educational theory and education management, comprehensive education, and higher education all have frequencies greater than 1,000 in reference and citation, but the rankings slightly vary. On the whole, the educational technology is closely linked with other education-related disciplines, and there is frequent interaction between disciplines. The educational technology continuously absorbs theories and methods of other disciplines of pedagogy, while other related disciplines of pedagogy also learn from the educational technology for their own development.

- In the process of knowledge production, educational technology actively learns from other disciplines: In addition to pedagogy-related disciplines, educational technology frequently exchanges with psychology, library information and digital libraries, and computer science etc. The knowledge of these disciplines have injected new ideas into the theory and methods of educational technology, and promoted its development.

- The interdisciplinary topics of educational technology and library, information and digital library are widely distributed: Taking the subject of library information and digital library as an example, the cross-cutting themes of educational technology and other disciplines are analyzed. The study found that educational technology learns and absorbs the theories and methods of library and information science in visual analysis, data mining, mobile learning, learning analysis, and scientometrics. Interdisciplinary development has played a positive role. 


\section{$6 \quad$ References}

[1] Klaassen, R. G. (2018). Interdisciplinary education: A case study. European Journal of Engineering Education, 43(6): 842-859. https://doi.org/10.1080/03043797.2018.1442417

[2] Ren, Y. Q., Gu, X. Q. (2019). Educational technology: Questions and answers to discipline development. Educational Research, 40(1): 141-152.

[3] Sarma, S., Willcox, K. E., Lippel, P. H., MIT Online Education Policy Initiative. (2016). Online education: A Catalyst for Higher Education Reforms. (Final Report) [EB/OL]. Commentary by Stephen Downes, 4.

[4] Alvesson, M., Sandberg, J. (2013). Has Management Studies Lost Its Way? Ideas for More Imaginative and Innovative Research. Journal of Management Studies, 50(1): 128-152. https://doi.org/10.1111/j.1467-6486.2012.01070.x

[5] Cho, Y. (2017). Identifying interdisciplinary research collaboration in instructional technology. TechTrends, 61(1): 46-52. https://doi.org/10.1007/s11528-016-0124-6

[6] Chen, S. Y. (2014). Foundations of educational technology: Integrative approaches and interdisciplinary perspectives. Interactive Learning Environments, 22(3): 396-397. https://doi.org/10.1080/10494820.2013.865862

[7] Chang, Y. W., Huang, M. H. (2012). A study of the evolution of interdisciplinarity in library and information science: using three bibliometric methods. Journal of the Association for Information Science \& Technology, 63(1): 22-33.

[8] Porter, A., Cohen, A., Roessner, J. D., Perreault, M. (2007). Measuring researcher interdisciplinarity. Scientometrics, 72(1): 117-147. https://doi.org/10.1007/s11192-007-17 $\underline{00-5}$

[9] White, H. D., McCain, K. W. (1998). Visualizing a discipline: an author co-citation analysis of information science, 1972 -1995. Journal of the American Society for Information Science, 49(4): 327-355. https://doi.org/10.1002/(sici)1097-4571(19980401)4 9:4<327::aid-asi4>3.0.co;2-w

[10] Leydesdorff, L. (2006). Can scientific journals be classified in terms of aggregated journaljournal citation relations using the Journal Citation Reports? Journal of the American Society for Information Science and Technology, 57(5): 601-613. https://doi.org/10. 1002/asi.20322

[11] Agarwal, R. (2016). On the intellectual structure and evolution of ISR. Information systems research, 27(3): 471-477.

[12] Krapivsky, P. L., Redner, S. (2005). Network growth by copying. Physical Review E, 71(3): 142-154.

[13] Cai, J. D., Huang, R. H. (2010). The Interaction of Disciplines That Are Related to Educational Technology_A Research Based on Scientometrics. Open Education Research, 16(6): 48-53.

[14] Lan, G. S. (2017). Research on the Knowledge Mapping Construction of Research Frontier and Hotspot in the International Educational Technology__ Visualization Analysis of the Literature from 1960 to 2016 Based on 18 Kinds of SSCI Journals. Modern Distance Education, 3: 57-76.

[15] Liu, J. X., Meng, X. Z., Qi, Y., Chen, C.S. (2019). Studies on Interdisciplinarity of Educational Technology Based on Web of Science-covered Data. Modern Distance Education, 2: 14-24.

[16] Zhou, J., Yang, P., Wang, Y. W. (2017). Evaluation of the Research Output Competitiveness of Educational Technology Discipline in Resent 5 Years. Modern Educational Technology, 27(3): 27-33. 
[17] Yang, Z. K., Wu, D., Zheng, X. D. (2018). Education informatization 2.0: A key historical leap in information technology education in the new era. Educational Research, 39(4): 1622.

[18] Klein, J. T. (2000). A conceptual vocabulary of interdisciplinary science. Toronto: University of Toronto, 3-4.

[19] Karal, H., Bahcekapili, T. (2010). New perspective to educational technology: interdisciplinary cooperation "an example of faculties of education and engineering". Turkish Online Journal of Educational Technology, 9(1): 132-142.

\section{Authors}

Junxiao Liu, was born in February 1981. She is a PhD student at the faculty of education and an associate research librarian of library, Shandong normal university in P. R. China. Recent research interests include interdisciplinary education technology and scientometrics.

Xiangzeng Meng, corresponding author, was born in September 1962.He received his PhD 's degree from Beijing University of Posts and Telecommunications in 2004. He is professor at the School of Journalism and Media, Shandong normal university in P. R. China.

Changsheng Chen, was born in October 1984. He is a lecturer of Shandong youth university of political science in P. R. China and a PhD student at the faculty of education, Shandong normal university.

Article submitted 2020-01-22. Resubmitted 2020-02-07. Final acceptance 2020-02-10. Final version published as submitted by the authors. 